\title{
Prospective associations between ECG abnormalities and death or myocardial infarction in a cohort of 980 employed, middle-aged Swedish men
}

\author{
Lennart Dimberg $^{1^{*}}$ D, Bo Eriksson ${ }^{2^{\wedge}}$ and Per Enqvist ${ }^{1}$
}

\begin{abstract}
Background: In 1993, 1000 randomly selected employed Swedish men aged 45-50 years were invited to a nurseled health examination with a survey on life style, fasting lab tests, and a 12-lead ECG. A repeat examination was offered in 1998. The ECGs were classified according to the Minnesota Code. Upon ethical approval, endpoints in terms of $\mathrm{MI}$ and death over 25 years were collected from Swedish national registers with the purpose of analyzing the independent association of ECG abnormalities as risk factors for myocardial infarction and death.

Results: Seventy-nine of 977 participants had at least one ECG abnormality 1993 or 1998.

One hundred participants had a first Ml over the 25 years. Odds ratio for having an $\mathrm{Ml}$ in the group that had one or more ECG abnormality compared with the group with two normal ECGs was estimated to $3.16 .95 \% \mathrm{Cl}(1.74 ; 5.73), p$ value 0.0001 .

One hundred fifty-seven participants had died before 2019. For death, similarly no statistically significant difference was shown, OR $1.52,95 \% \mathrm{Cl}(0.83 ; 2.76)$.

Conclusions: Our study suggests that presence of ST- and R-wave changes is associated with an independent 3-4fold increased risk of Ml after 25 years follow-up, but not of death. A 12-lead resting ECG should be included in any MI risk calculation on an individual level.
\end{abstract}

Keywords: Mortality, Myocardial infarction, Cohort study, Middle-aged men, Risk factors, Resting ECG

\section{Background}

The World Health Organization (WHO) claims that cardiovascular diseases mainly heart attacks and stroke are responsible for more than half of the deaths in Europe, and that $80 \%$ of premature heart disease and stroke events are preventable [1]. Traditional risk factors for heart disease include male sex, high blood pressure, tobacco smoking, diabetes, obesity, abnormal blood lipids,

\footnotetext{
* Correspondence: Ldimberg@aol.com

Bo Eriksson is deceased.

'Department of Public Health and Community Medicine, the Sahlgrenska Academy, University of Gothenburg, Box 454, SE-405 30 Gothenburg, Sweden

Full list of author information is available at the end of the article
}

and physical inactivity. The Framingham Heart Study started in 1948 and was early to identify and recognize the importance of these risk factors, some of which were recognized already by Galen (150 AD) [2, 3]. The Multinational MONItoring of trends and determinants in CArdiovascular disease (MONICA) have used them to explain national variations of heart attacks and stroke at a population level [4].

ECG is a common investigative method at regular health examinations as well as upon symptoms from the heart such as palpitations and chest pain. A British study of 4739 apparently healthy individuals found ECG abnormalities in $32 \%$ of the middle-aged men [5]. In a systematic review of diabetes patients, Jonas et al. (2018) 
identified zero randomized controlled studies with resting ECG and cardiovascular outcomes. However, based on findings from five cohort studies, they found small improvements in risk classification for prediction of cardiovascular outcomes by adding ECG to traditional risk factors [6]. Based on this review, the US Preventive Services Task Force (USPSTF) recommends against screening with ECG among apparently healthy primary care patients. They do however recommend screening for those with other concomitant cardiovascular risk factors (intermediate or higher risk).

In 1993, a joint health project, the Coeur study, between a French and a Swedish automotive company, investigated 1000 randomly selected middle-aged French men and Swedish men with focus on risk factors for cardiovascular disease [7]. A major cause was to look into the French paradox of coronary heart disease (CHD). This paradox means that Frenchmen in general, in spite of a less healthy lifestyle with more smokers and intake of cheese and wine, supposedly are less prone to myocardial infarction (MI) compared to men from the Northern countries, for example, Sweden. The aforementioned has been suggested from the MONICA studies $[8,9]$. In 1998, we offered a redo of the baseline investigation and several reports have been published looking at the association between the Framingham Risk Index, a common composite risk index for MI, and marital status, life events, and psychological well-being [10-12]. Additional publications from the early phase of the Coeur study concern national differences of carotid artery wall structure between Swedish and French men as well as the association of different indices of overweight and the FRI [13, 14]. In 1999, the international collaboration was terminated, and our project has since focused solely on the Swedish cohort. More recently (2019), Dimberg et al. investigated the association between traditional risk factors and MI and death based on 22 years of accumulated endpoints in terms of first MI and death in the Swedish men [15]. This study confirmed the association of traditional risk factors, specifically with the Framingham Risk Index, and MI, OR of the fifth to first quintile of $23(95 \% \mathrm{CI}=5.42,96.9)$ but weaker with all-cause death, OR $3.2(95 \% \mathrm{CI}=1.65$, 6.08). However, traditional risk factors only explained $22 \%$ of the variation of MI.

Consequently, we have reason to believe that other independent risk factors possibly such as abnormalities in 12-lead resting ECG may add to this explanation.

This study is a follow-up of the cohort of Swedish men with focus on specific ECG abnormalities and their subsequent associations with myocardial infection (MI) and/or death.

The long follow-up period (now 25 years) and the baseline documentation of a multitude of traditional and non-traditional risk factors allow for the additional risk estimate of ECG abnormalities in a relatively healthy male working population. We therefore expect our findings to benefit the risk prediction of abnormal ECGs at routine health examinations.

The aims are as follows:

- To investigate statistical associations between ECG abnormalities (ECGA) found in resting ECG and the associated risk of death or MI over 25 years

- To calculate the possibly added value of ECGA to the Framingham index for prediction of death and MI throughout this period

\section{Methods}

This study pertains to the Swedish cohort of 1000 randomly selected Swedish employed Caucasian men born between January 1, 1943, and January 1, 1948. They are part of the Coeur project, a prospective longitudinal study started in 1993. At that time, information was collected at a nurse-led health examination and included fasting laboratory data, body measurements, resting blood pressure, pulse, and a 12-lead ECG. The nurse or assistant also supervised the completion of a selfadministered questionnaire with questions on health, lifestyle, diet and alcohol intake, mental health, working conditions, stress, and more. This part of the study is detailed in the paper by Simon et al. (1997) [7]. In this research, we have estimated the cardiovascular risk by the Framingham Risk Score. It calculates an individual's 10year risk for cardiovascular events. The Framingham Risk Index (FRI) is validated for Americans, and subgroups of Americans, both gender, European Americans, and African Americans [10]. The index was calculated in steps according to Andersson [16].

We used the following baseline data for the present analysis: age; married/single/divorced; smoking status (yes/no); systolic blood pressure (SBP) in $\mathrm{mmHg}$; pulse rate in beats/min; serum high-density lipoprotein cholesterol (HDL-C) in $\mathrm{mmol} / \mathrm{L}$; serum triglycerides (TG) in $\mathrm{mmol} / \mathrm{L}$, diabetes mellitus (yes/no); left ventricular hypertrophy (yes/no); Framingham Risk Index; alcohol intake in grams/week; body mass index (BMI) in $\mathrm{kg} / \mathrm{m}^{2}$; and sagittal abdominal diameter in centimeters and ECG. Smoking habits were analyzed by the question about current smoking (yes/no) defined as "Do you presently smoke?"

\section{ECG collection and analysis}

In 1993, the 12-lead resting ECGs and laboratory tests were performed by two nurses (one in Gothenburg and one in Trollhättan) together with supervision of the survey completion. All ECGs were read and coded by the same laboratory technician [7]. The ECG investigation 
was conducted under a strict protocol, developed by professor Sverker Jern. All ECGs were classified by The Minnesota Code Classification System for Electrocardiographic Findings (MC); see Table 1 [17].

In 1998, all 1000 Swedish participants were summoned for another nurse-led health check-up including a new ECG. We used the 1993 ECG protocol and the previous laboratory technician (ML) classified each ECG according to $\mathrm{MC}$.

\section{The 25-year follow-up, end-point information}

In 2019, after a new ethical approval, we contacted The National Board of Health and Welfare (Socialstyrelsen), to gain access to the Cause of Death Register data for our 1000 participants and recorded cause of death according to the International Classification of Diseases (ICD) manual. Furthermore, we contacted the Swedish national myocardial infarction registry, also known as Swedeheart to obtain information about heart attacks in our cohort. The registry collects information from all Swedish hospitals that care for patients with acute coronary artery disease and all patients undergoing coronary angiography, catheter intervention, or open-heart surgery [18].

The Joint ESC/ACCF/AHA/WHF task force has described myocardial infarction as myocardial cell death due to prolonged ischemia, and it is a consequence of coronary artery disease [19]. To define myocardial infarction, we used code 410 of the International Classification of Diseases Ninth Revision (ICD 9), and codes I21-I23 of the Tenth Revision (ICD 10) by World Health Organization [20].

\section{Statistical analysis}

The cumulative incidence from baseline to the end of follow-up was estimated as a percentage with confidence limits estimated using the conventional method. Confidence intervals were estimated using exact probability methods when requested due to small numbers. To

Table 1 An overview of the Minnesota Code Classification System for Electrocardiographic Findings

\begin{tabular}{ll}
\hline Minnesota Code & ECG abnormality \\
\hline $1-1-1 \ldots .1-3-6$ & Q waves \\
$2-1 \ldots \ldots 3-5$ & QRS axis deviation \\
$3-1 \ldots \ldots 3-3$ & High amplitude R waves \\
$4-1-1 \ldots 4-4$ & ST junction $(J)$ and segment depression \\
$5-1 \ldots . .5-4$ & T wave items \\
$6-1 \ldots . .6-8$ & A-V conduction defect \\
$7-1-1 \ldots 7-8$ & Ventricular conduction defect \\
$8-1-1 \ldots 8-9$ & Arrhythmias \\
& Miscellaneous including ST-segment elevation (9-2) \\
\hline
\end{tabular}

study the associations between ECG abnormalities (ECGA) and other risk factors by category, we used conventional means with confidence limits, again with exact methods when necessary. To study different models with the dichotomous variables Death or MI as a dependent variable and different combinations of risk factors as independent variables, logistic regressions were used. All such models except one included the dichotomous ECGA. One model contained only the FRI variable as independent. Continuous variables like FRI, SBP, and BMI were represented in the model with dummy variables for the five quintiles of the variable distribution. The results considered in the logistic models were the odds ratios (OR) and a Pseudo-R2. The odds of an event is the risk for the event divided by 1 minus the risk, i.e., the probability for the event divided with the probability for nonoccurrence. If the risk is low, we can say that the OR is a fair approximation of the risk ratio (RR) or relative risk. The estimates of OR are given with appropriate confidence intervals.

The logistic regression uses a generalized linear model. We cannot use the traditional R2 to assess the goodness-of-fit of the model. Several Pseudo-R2 have been proposed. The one used here is the one proposed by Mc Fadden [21] that can be interpreted similarly to the R2 for a linear model. The Pseudo-R2 results are expressed as percentages in this paper. Calculations were performed using the software Stata version 15.

Variable definitions, outcomes, and endpoints (dependent variable) include:

Death 157, deaths reported First Myocardial Infarctions, $100 \mathrm{MI}$ reported

\section{Explanatory (independent) variables, components of Framingham Risk Index}

Explanatory variables include systolic blood pressure (mmHg), smoking (yes/no), HDL cholesterol/Tot cholesterol, left ventricular hypertrophy (yes/no), age, and diabetes (yes/no).

\section{Additional explanatory variables}

Additional explanatory variables include diastolic blood pressure $(\mathrm{mmHg})$, heart rate (beats/min), triglycerides $(\mathrm{mmol} / \mathrm{l})$, glycemia $(\mathrm{mmol} / \mathrm{l})$, body mass index (BMI), waist/hip ratio, sagittal diameter $(\mathrm{cm})$, total alcohol consumption (g/week), blue collar workers (yes/no), married or cohabiting (yes/no), noisy work environment (yes/no), hypertension (yes/no), family heart attack (yes/no)

\section{Results}

The study participants and ECG outcome

The sample selected for the baseline survey included 1000 men aged $45-50$ years. Of these, 3 did not provide 
any information. Another 20 had substantial numbers of missing values; particularly, they did not have results from any of the two ECG investigations in 1993 and 1998 (Table 2). Totally, 108 participants had only one ECG, 72 in 1993 and 36 in 1998. ECG means electrocardiogram. ECGA means electrocardiogram with abnormality.

As shown in Table 3, surprisingly, category 9 with only one registered and normal ECG compared to category 0 with two normal ECGs had a significantly higher risk of death, but not of MI. As expected, category 1 with one or more ECG abnormalities had over double cumulative percentage than category 0 .

Table 4 only shows statistically significant differences in higher blood pressure (systolic and diastolic) between those with normal ECGs (category 0) and those with ECG abnormalities (category 1).

Table 5 shows a statistically significantly higher percentage of baseline hypertension in those with ECGA (category 1) compared to those with normal ECG (category 0 ).

No statistically significant risk difference between category 1 and category 0 was seen for blue collar workers $(\mathrm{OR}=1.02 ; p=0.93)$.

\section{Regression models}

The results from logistic regression models are presented in Tables 6 and 7. The two tables have identical structure and content. Table 6 gives the results for the estimation in a series of models for the outcome, dependent, variable death whereas Table 7 shows the corresponding for the outcome "first MI."

The independent variables in the models $1-5$, from top to bottom in the two tables, are:

1. Category of ECG

2. Quintiles of the FRI

3. Category of ECG together with FRI

Table 2 Electrocardiographic abnormalities (ECGA) of the 977 cohort participants, men aged 45-50, in 1993 (baseline) and at follow up in 1998

\begin{tabular}{lllll}
\hline \multirow{2}{*}{ ECG 1993 } & ECG 1998 & & & \\
\cline { 2 - 5 } & ECGA no & ECGA yes & Missing & Total \\
\hline ECGA no & 790 & 29 & 72 & 891 \\
ECGA yes & 19 & 15 & 7 & 41 \\
Missing & 36 & 9 & $(23)^{\mathrm{a}}$ & 45 \\
Total & 845 & 53 & 79 & $977(1000)^{\mathrm{b}}$ \\
\hline
\end{tabular}

Classification of ECG outcomes

The 977 participants were classified into three ECG categories as follows: ECG category 0, ECG performed in 1993 and 1998, no ECGA, $(n=790)$; ECG

category 1, ECG performed in 1993 and/or 1998, one or more abnormalities (n = 79); and ECG category 9, ECG performed in 1993 or 1998 without

abnormality $(n=108)$

${ }^{a} 23$ non-informative

b $1000-23$ informative
4. Quintiles of ECG together with the variables that are included in the FRI, here considered separately in linear form

5. Quintiles of ECG, the FRI variables in linear form and the additional; total alcohol, heart rate, BMI, waist/hip ratio, and sagittal diameter

For the two last models, the tables contain only the estimates for ECGA and total model Pseudo R2.

The main interest is the association between death and ECG abnormality. We do not find a statistically significant association in any of the models in Table 6 . The lack of statistical significance with OR between 1.4 and 1.6 is largely due to the small number of ECGA. The significant OR comparing the categories coded 0 and 9 is difficult to interpret since the last category is problematically defined.

The Pseudo-R2s are generally low even for the largest model (13.8). It shall be noted though that the ECGA variable has some importance. However, even at the low level, the model with ECGA and the individual FRI variables is better than the model where the calculated FRI is used.

For MI (Table 7), the OR for comparisons of ECGA = 0 and ECGA $=1$ are all statistically significant whereas those comparing ECGA $=0$ and ECGA $=9$ are not. ECG investigation is statistically significantly associated with MI but not with death. The OR for ECGA are all fairly high, between 2.8 and 4.2, regardless of the model.

The R2s are higher for MI than for death and the model with individual FRI is higher than the model with computed FRI, same as for death. The highest R2 is almost $25 \%$, which is higher than $13 \%$ for death. Both, however, shall be considered as relatively low.

Tables 8 and 9 show the distributions of ECG abnormalities by types according to the Minnesota classification.

Strongest association with MI was Q, QS pattern $(1 / 3=$ $33 \%$ ) (as expected) and STJ depression $(4 / 18=22 \%)$, but the association with the more common incomplete right bundle branch block $(5 / 23=22 \%)$ and intraventricular block $(1 / 11=9 \%)$ were surprising to us, although based on small numbers and therefore not significant at that level.

Also surprising were the strong associations with death of STJ depression $(4 / 5=80 \%)$ and intraventricular block $(4 / 11=36 \%)$ with the same caution of interpretation.

The study started in 1993 when the participants were 45-50 years old and finished in 2018 when they were $70-75$ years old. The cumulative deaths, all causes, by age at death in category 9 (only first ECG) compared to category 1 (first and second ECG with at least 1 abnormal) and category 0 (two normal ECGs) indicate that category 9 over 25 years follow-up was at highest risk, as shown in Fig. 1. 
Table 3 Estimated cumulative incidences (percentages) and absolute numbers of deaths and first Ml for participants followed for 25 years by category (95\% confidence intervals in brackets)

\begin{tabular}{lllll}
\hline ECG category & $\begin{array}{l}\text { Death }(\boldsymbol{n}=\mathbf{1 5 7}) \\
\text { Cumulative percentage }\end{array}$ & $\begin{array}{l}\text { Infarction }(\boldsymbol{n}=100) \\
\text { Cumulative percentage }\end{array}$ & $\begin{array}{l}\text { Deaths } \\
\text { Number of cases }\end{array}$ & $\begin{array}{l}\text { First MI } \\
\text { Number of cases }\end{array}$ \\
\hline $0(n=790)$ & $13.9(11.5 ; 16.3)$ & $8.35(6.42 ; 10.3)$ & 110 & 66 \\
$1(n=79)$ & $20.8(11.5 ; 30.0)$ & $22.4(13.8 ; 31.9)$ & 16 & 17 \\
$9(n=108)$ & $27.6(18.5 ; 36.6)$ & $12.6(5.83 ; 19.4)$ & 27 & 12 \\
Total & $15.6(13.3 ; 17.57)$ & $10.2(8.3 ; 12.1)$ & $153^{\mathrm{a}}$ & $95^{\mathrm{b}}$ \\
\hline
\end{tabular}

ECG category 0, ECG performed in 1993 and 1998, no ECGA; ECG category 1, ECG performed in 1993 and/or 1998 with one or more abnormalities; and ECG category 9, ECG performed in 1993 or 1998 without abnormality

a 4 deaths among the 23 non-informatives

$b_{5}$ Mls among the 23 non-informatives

Contrary to the cumulative deaths and correspondingly, Fig. 2 shows the significant outcome of MIs highest in category 1 (at least one abnormal ECG).

\section{Discussion}

A major finding is that there is a statistically significant association between resting ECG abnormalities (ECGA) at baseline as a group and the cumulative incidence of myocardial infarction over 25 years also after adjustment for traditional risk factors. The ORs quantifying the comparisons are all high, between 2.8 and 4.2, regardless of the regression model used.

The benefit of ECGA compared to traditional risk factors following adjustment indicates that ECGA may not follow the same arteriosclerotic pathway as the Framingham Risk Index.

However, the Pseudo-R2, which explains the proportion of the variation, was for ECGA only $2.1 \%$ compared to FRI with $8.6 \%$. The model combining ECGA and FRI has a Pseudo-R2 at $11 \%$, still low.

There is no statistically significant association between ECGA and the outcome of death.
In 2018, based on a review of the literature, the US Preventive Services Task Force (USPSTF) published a recommendation not to use ECG for screening in previously healthy men without any other cardiovascular risk factor [22]. Our study and others though indicate that resting ECGs add value for the predictive model of the risk of future myocardial infarction [6, 23-32].

It is important to realize the difference between using ECG for screening of an assumed healthy population and using it as a tool among others in clinical practice. Using the present data as an example, a population screening would have a sensitivity of $20 \%$, i.e., only one in five would be classified as a potential MI patient. Further, there will be about $75 \%$ false positive, unnecessarily requiring some attention. Population screening aims at finding potential cases early and an important requirement also is that there is some action that can be taken, which hardly is the case in the present study.

In clinical work, the assumptions are different with higher sensitivity and less false positive due the higher prevalence of persons with high risk.

Table 4 Estimated means with 95\% confidence intervals in brackets for continuous baseline risk factors by ECG category

\begin{tabular}{llll}
\hline Risk factor & ECG category $\mathbf{0}(\boldsymbol{n}=\mathbf{7 9 0})$ & ECG category $\mathbf{1}(\boldsymbol{n}=\mathbf{7 9})$ & ECG category $\mathbf{9}(\boldsymbol{n}=\mathbf{1 0 8})$ \\
\hline Framingham Risk Index & $0.089(0.085-0.093)$ & $0.108(0.091-0.128)$ & $0.094(0.080-0.108)$ \\
Systolic blood pressure $(\mathrm{mmHg})$ & $116(115-118)$ & $124(120-128)$ & $116(113-119)$ \\
Diastolic blood pressure $(\mathrm{mmHg})$ & $75(74-75)$ & $79(76-83)$ & $74(71-76)$ \\
Heart rate (beats per minute) & $63(63-64)$ & $63(61-66)$ & $62(61-65)$ \\
HDL chol/total cholesterol & $0.212(0.207-0.216)$ & $0.226(0.197-0.255)$ & $0.207(0.193-0.222)$ \\
Triglycerides (mmol/l) & $1.52(1.46-1.58)$ & $1.53(1.31-1.74)$ & $1.60(1.38-1.82)$ \\
Glycemia (mmol/l) & $5.47(5.40-5.54)$ & $5.58(5.27-5.89)$ & $5.39(5.22-5.57)$ \\
Body mass index BMl & $25.8(25.5-26.0)$ & $25.4(24.6-26.2)$ & $25.0(24.4-25.6)$ \\
Waist/hip ratio & $0.933(0.929-0.937)$ & $0.923(0.910-0.936)$ & $0.930(0.919-0.941)$ \\
Sagittal diameter (dm) & $2.03(2.02-2.05)$ & $2.02(1.95-2.08)$ & $1.98(1.93-2.02)$ \\
Alcohol consumption (g/week) & $51.5(47.4-55.6)$ & $52.2(41.1-63.3)$ & $54.3(41.7-66.9)$
\end{tabular}

ECG category 0, ECG performed in 1993 and 1998, no ECGA; ECG category 1, ECG performed in 1993 and/or 1998 with one or more abnormalities; and ECG category 9, ECG performed in 1993 or 1998 without abnormality 
Table 5 Estimated percentages of "yes" response, with confidence intervals in brackets for dichotomous risk factors by ECG category

\begin{tabular}{llll}
\hline Risk factor & ECG category $\mathbf{0}(\boldsymbol{n}=\mathbf{7 9 0})$ & ECG category $\mathbf{1}(\boldsymbol{n}=\mathbf{7 9})$ & ECG category $\mathbf{9}(\boldsymbol{n}=\mathbf{1 0 8})$ \\
\hline Blue collar workers & $39(36-43)$ & $39(27-50)$ & $36(26-46)$ \\
Married or cohabiting & $77(74-80)$ & $79(69-88)$ & $74(65-83)$ \\
Noisy work environment & $3.7(2.4-5.0)$ & $8.0(1.7-14.3)$ & $5.3(0.69-9.83)$ \\
Smoker & $28(25-31)$ & $26(16-36)$ & $30(20-39)$ \\
Diabetes at baseline & $0.008(0.001-0.014)$ & $0.039(0.000-0.084)$ & $0.042(0.000-0.0832)$ \\
Hypertension at baseline & $8.8(6.79-10.7)$ & $21(11.6-30.4)$ & $9.5(3.48-15.4)$ \\
Family heart attack & $23(20.0-25.8)$ & $29(18.8-39.9)$ & $27(18.2-36.4)$ \\
\hline
\end{tabular}

ECG category 0, ECG performed in 1993 and 1998, no ECGA; ECG category 1, ECG performed in 1993 and/or 1998 with one or more abnormalities; and ECG category 9, ECG performed in 1993 or 1998 without abnormality

It can be clinically relevant to examine healthy $45-50$ year-old men with ECG as one component among others when judging the risk for an MI.

Since no remedy exists for unspecific ECG abnormalities, such findings may only be used to emphasize the important prevention of a healthy lifestyle.

Due to the few cases in the subgroups of the ECG abnormalities, it is not meaningful to evaluate statistically the impact of most Minnesota Code subgroups on the specific risk of MI.

Other studies suggest that prolonged QRS complexes (24-27) and negative T-waves $(24,28-29)$ lead to increased risks. This is not contradicted by our study.

In addition, we also find that STJ depression shows an increased but not statistically significant risk for MI and death.

Table 6 Results for regression models with death as a dependent variable with ECGA and additional independent variables of the 977 cohort participants of men aged 45-50 at baseline in 1993 followed for 25 years

\begin{tabular}{|c|c|c|c|c|c|}
\hline Death model & $\begin{array}{l}\text { Independent } \\
\text { variable(s) }\end{array}$ & $\begin{array}{l}\text { Estimated } \\
\text { OR }\end{array}$ & $\begin{array}{l}95 \% \text { confidence interval } \\
\text { for OR }\end{array}$ & $\begin{array}{l}p \text { value for } \\
\text { OR }\end{array}$ & $\begin{array}{l}\text { Pseudo-R2 for } \\
\text { model, } \%\end{array}$ \\
\hline \multirow[t]{3}{*}{ ECGA only (model 1) } & $E C G A=0$ & Reference & & & 1.4 \\
\hline & $\mathrm{ECGA}=1$ & 1.52 & $(0.83 ; 2.76)$ & 0.106 & \\
\hline & $E C G A=9$ & 2.09 & 1.263 .46 & 0.001 & \\
\hline \multirow[t]{5}{*}{ FRI only (model 2) } & $\mathrm{FRI}=1$ & Reference & & & 2.9 \\
\hline & $\mathrm{FRI}=2$ & 0.68 & $(0.35 ; 1.31)$ & 0.248 & \\
\hline & $\mathrm{FRI}=3$ & 0.77 & $(0.40 ; 1.46)$ & 0.418 & \\
\hline & $\mathrm{FRI}=4$ & 1.51 & $(0.66 ; 2.67)$ & 0.154 & \\
\hline & $\mathrm{FRI}=5$ & 2.16 & $(1.25 ; 3.73)$ & 0.006 & \\
\hline \multirow[t]{8}{*}{ ECGA and FRI (model 3) } & $E C G A=0$ & Reference & & & 3.8 \\
\hline & $E C G A=1$ & 1.58 & $(0.85 ; 2.93)$ & 0.146 & \\
\hline & $E C G A=9$ & 1.84 & $(1.06 ; 3.20)$ & 0.030 & \\
\hline & $\mathrm{FRI}=1$ & Reference & & & \\
\hline & $\mathrm{FRI}=2$ & 0.68 & $(0.35 ; 1.32)$ & 0.256 & \\
\hline & $\mathrm{FRI}=3$ & 0.69 & $(0.36 ; 1.34)$ & 0.272 & \\
\hline & $\mathrm{FRI}=4$ & 1.40 & $(0.75 ; 2.51)$ & 0.246 & \\
\hline & $\mathrm{FRI}=5$ & 2.12 & $(1.22 ; 3.69)$ & 0.007 & \\
\hline \multirow[t]{3}{*}{ ECGA and FRI variables (model 4) } & $E C G A=0$ & Reference & & & 8.3 \\
\hline & $E C G A=1$ & 1.41 & $(0.73 ; 2.73)$ & 0.301 & \\
\hline & $E C G A=9$ & 1.84 & $(1.01 ; 3.37)$ & 0.048 & \\
\hline \multirow{3}{*}{$\begin{array}{l}\text { ECGA and all explanatory variables } \\
\text { (model 5) }\end{array}$} & $E C G A=0$ & Reference & & & 13.8 \\
\hline & $E C G A=1$ & 1.42 & $(0.69 ; 3.02)$ & 0.247 & \\
\hline & $E C G A=9$ & 2.52 & $(1.27 ; 4.97)$ & 0.021 & \\
\hline
\end{tabular}

ECG category 0, ECG performed in 1993 and 1998, no ECGA; ECG category 1, ECG performed in 1993 and/or 1998 with one or more abnormalities; and ECG category 9, ECG performed in 1993 or 1998 without abnormality 
Table 7 Results for regression models with first $\mathrm{MI}$ as a dependent variable with ECGA and additional independent variables of the 977 cohort participants of men aged 45-50 at baseline in 1993 followed for 25 years

\begin{tabular}{|c|c|c|c|c|c|}
\hline Infarct models & $\begin{array}{l}\text { Independent } \\
\text { variable(s) }\end{array}$ & $\begin{array}{l}\text { Estimated } \\
\text { OR }\end{array}$ & $\begin{array}{l}95 \% \text { confidence interval } \\
\text { for OR }\end{array}$ & $\begin{array}{l}p \text { value for } \\
\text { OR }\end{array}$ & $\begin{array}{l}\text { Pseudo-R2 for } \\
\text { model, } \%\end{array}$ \\
\hline \multirow[t]{3}{*}{ ECGA only (model 1) } & $E C G A=0$ & Reference & & & 2.11 \\
\hline & $\mathrm{ECGA}=1$ & 3.16 & $(1.74 ; 5.73)$ & 0.000 & \\
\hline & $E C G A=9$ & 1.59 & $(0.82 ; 3.06)$ & 0.168 & \\
\hline \multirow[t]{5}{*}{ FRI only (model 2) } & $\mathrm{FRI}=1$ & Reference & & & 8.57 \\
\hline & $\mathrm{FRI}=2$ & 6.35 & $(1.40 ; 28.8)$ & 0.017 & \\
\hline & $\mathrm{FRI}=3$ & 9.27 & $(2.11 ; 40.7)$ & 0.003 & \\
\hline & $\mathrm{FRI}=4$ & 14.3 & $(3.24 ; 61.5)$ & 0.000 & \\
\hline & $\mathrm{FRI}=5$ & 25.4 & $(6.02 ; 106)$ & 0.000 & \\
\hline \multirow[t]{8}{*}{ ECGA and FRI (model 3) } & $E C G A=0$ & Reference & & & 10.6 \\
\hline & $\mathrm{ECGA}=1$ & 2.82 & $(1.51 ; 5.28)$ & 0.001 & \\
\hline & $E C G A=9$ & 1.43 & $(0.70 ; 2.89)$ & 0.324 & \\
\hline & $\mathrm{FRI}=1$ & Reference & & & \\
\hline & $\mathrm{FRI}=2$ & 6.22 & $(1.36 ; 28.3$ & 0.018 & \\
\hline & $\mathrm{FRI}=3$ & 7.98 & $(1.79 ; 35.5)$ & 0.006 & \\
\hline & $\mathrm{FRI}=4$ & 14.1 & $(3.28 ; 60.6)$ & 0.000 & \\
\hline & $\mathrm{FRI}=5$ & 24.3 & $(5.77 ; 103)$ & 0.000 & \\
\hline \multirow[t]{3}{*}{ ECGA and FRI variables (model 4) } & $E C G A=0$ & Reference & & & 14.9 \\
\hline & $\mathrm{ECGA}=1$ & 3.43 & $(1.74 ; 6.76)$ & 0.000 & \\
\hline & $E C G A=9$ & 1.24 & $(0.57 ; 2.70)$ & 0.579 & \\
\hline \multirow{3}{*}{$\begin{array}{l}\text { ECGA and all explanatory variables } \\
\text { (model 5) }\end{array}$} & $E C G A=0$ & Reference & & & 24.6 \\
\hline & $\mathrm{ECGA}=1$ & 4.22 & $(1.85 ; 9.64)$ & 0.001 & \\
\hline & $\mathrm{ECGA}=9$ & 1.18 & $(0.47 ; 2.96)$ & 0.719 & \\
\hline
\end{tabular}

ECG category 0, ECG performed 1993 and 1998, no ECGA; ECG category 1, ECG performed 1993 and/or 1998 with one or more abnormalities; and ECG category 9, ECG performed 1993 or 1998 without abnormality

Prolonged QTc (pulse-corrected QT-time) has been associated with higher risk of MI and death [32-35]. Prolonged QTc is not classified in the Minnesota Code and has therefore not been studied here.

An unexpected finding was that the category 9 participants (only one EGG taken and without abnormality) had a double risk of death, $28 \%$ vs $14 \%,(p<0.05)$. We have no satisfactory explanation for this discovery. Some participants may have been skeptical or ill and refrained from the second followup. One thought was that this phenomenon might have been caused by death between the two examinations (in 1993 and 1998) but as seen in Fig. 2, this is not the explanation.

Another finding shown in Tables 5 and 6 is that there is more information in the variables included in FRI if they are studied separately than in the combined risk index (FRI). The Pseudo-R2 for MI goes from 11 to 15\% and for death from 3.8 to $8.3 \%$.

\section{Limitations and strengths Strengths}

The original 1000 men were randomly selected from a well-defined population of male workers followed over a very long time ( 25 years). Very few rejected to participate. The nurses and health professionals were specially trained and well-defined methods were used. The procedures for baseline information acquisition were carefully developed based on current standards. Accurate information about the endpoints was available through national registers with quality control to contain valid data. The internal validity of the study and its results have throughout been carefully secured.

\section{Limitations}

The external validity, i.e., validity for other populations with other contextual structures, is clearly limited. The study is confined to males in a certain age range in a particular industry and certain country. The comparably small sample size and, therefore, the small number of outcomes events are limited and are a problem to some extent.

The study is also limited by the use of the Framingham Risk Index in the original Coeur study since this index has been superseded by better predictive tools such as QRISK2 [36] and the use of biomarkers [37]. However, in a 25-year longitudinal study, the analysis is 
Table 8 Number of ECG deviations in 1993 electrocardiographic abnormalities and myocardial infarction and death in 964 middleaged, employed men in 1993 followed for 25 years

\begin{tabular}{|c|c|c|c|c|c|c|c|c|}
\hline $\begin{array}{l}\text { Minnesota } \\
\text { Code }\end{array}$ & Explanation & $\begin{array}{l}\text { Investigated } \\
\text { persons }\end{array}$ & $\begin{array}{l}\text { Observed } \\
\text { findings }\end{array}$ & $\begin{array}{l}\text { Findings } \\
\text { with death }\end{array}$ & $\begin{array}{l}\text { Findings } \\
\text { with infarct }\end{array}$ & $\begin{array}{l}p \text { value } \\
\text { death }\end{array}$ & $\begin{array}{l}p \text { value } \\
\text { infarct }\end{array}$ & $\begin{array}{l}\text { ECG findings both in } \\
1993 \text { and } 1998\end{array}$ \\
\hline \multicolumn{9}{|c|}{$\mathrm{Q}$ and $\mathrm{QS}$ patterns } \\
\hline $1: 1$ & $\begin{array}{l}\text { Q and QS pattern (\% with } \\
\text { endpoint) }\end{array}$ & 964 & 3 & $1(33)$ & $2(67)$ & & 0.000 & 2 \\
\hline $1: 2$ & $\begin{array}{l}\text { Q, QS, and QSR pattern (\% } \\
\text { with endpoint) }\end{array}$ & 964 & 10 & $1(10)$ & $2(20)$ & & & 5 \\
\hline \multicolumn{9}{|c|}{ STJ and segment depression } \\
\hline $4: 1$ or $4: 2$ & $\begin{array}{l}\text { STJ depression (\% with } \\
\text { endpoint) }\end{array}$ & 947 & 5 & $4(80)$ & $3(60)$ & 0.000 & 0.000 & 1 \\
\hline \multicolumn{9}{|l|}{ T wave items } \\
\hline $5: 1$ or $5: 2$ & $\begin{array}{l}\text { T wave negative or } \\
\text { biphasic (\% w. endpoint) }\end{array}$ & 947 & 7 & $3(43)$ & $2(29)$ & 0.004 & 0.075 & 3 \\
\hline \multicolumn{9}{|c|}{ AV conduction defect } \\
\hline $6: 1$ & Complete AV block & 964 & 0 & & & & & \\
\hline $6: 4: 1$ & $\begin{array}{l}\text { Wolf-Parkinson-White } \\
\text { pattern }\end{array}$ & 964 & 0 & & & & & \\
\hline $6: 8$ & Artificial pacemaker & 964 & 0 & & & & & \\
\hline \multicolumn{9}{|c|}{ Ventricular conduction defect } \\
\hline $7: 1: 1$ & $\begin{array}{l}\text { Complete left bundle } \\
\text { branch block }\end{array}$ & 964 & 1 & 0 & 0 & & & 0 \\
\hline $7: 2: 1$ & $\begin{array}{l}\text { Complete right bundle } \\
\text { branch block }\end{array}$ & 964 & 7 & $1(14)$ & $2(29)$ & & & 4 \\
\hline $7: 3$ & Incomplete RBB & 964 & 23 & $1(4)$ & $5(22)$ & & & 11 \\
\hline $7: 4$ & Intraventricular block & 962 & 11 & $4(36)$ & $1(9)$ & 0.004 & & 0 \\
\hline $7: 6$ & Incomplete LBB & 919 & 8 & $1(13)$ & $1(13)$ & & & \\
\hline
\end{tabular}

The $p$ values refer to death and infarct risk comparisons between persons with and without ECG abnormalities. Only $p$ values smaller than 0.100 are shown. Note that the $p$ values themselves are due to variation. Even one single finding more or less might change the $p$ value substantially.

necessarily restricted to the original risk measure. Important to point out is that even QRISk2 at its core include the traditional risk factors from the Framingham study. Another limitation is that the Minnesota Code used for classification does not register QTc.

\section{Confounding}

The main research question concerns the statistical association between the risk and results of the ECG investigations. This relation can be confounded by several variables. Many of these were observed at baseline such as age, smoking status, alcohol consumption, weight, height, and systemic blood measurements. Most of these are correlated with each other and with the risk of MI and death. Therefore, the crude correlation between risk and ECGA is confounded by a manifold variable. Among these, some are known and possible to observe. Others are known but not possible to observe and yet others have not even been imagined. The first mentioned group can be adjusted for using different regression models. For this paper, we have tried several models. An important finding is that the OR for ECG abnormality remains reasonably stable, OR about 3.4, regardless of the model. This is an indication that the main results are not seriously confounded by the variables used in this study.

\section{Bias}

A bias is a systematic error that has similar size and direction for a group of measurements. Several biases could influence the results. For example, laboratory results might be biased due to incorrect calibrations; questions for self-reporting can be formulated to give biased information. We have tried to address some of these biases by careful quality control and the use of certified laboratories in our study.

In longitudinal studies, it is possible for both confounding and biases to occur since it is difficult to account for changes in an individual's habits or health status over the whole, in this case, 25-year period.

Confounding factors in this study would include not accounting for the eventuality that participants' behaviors might change over time, for example smoking less, losing or gaining weight as well as medical treatment of 
Table 9 Number of ECG deviations in 1998 follow-up

\begin{tabular}{|c|c|c|c|c|c|c|c|}
\hline $\begin{array}{l}\text { Minnesota } \\
\text { Code }\end{array}$ & Explanation & $\begin{array}{l}\text { Investigated } \\
\text { persons }\end{array}$ & $\begin{array}{l}\text { Observed } \\
\text { findings }\end{array}$ & $\begin{array}{l}\text { Findings with } \\
\text { death }\end{array}$ & $\begin{array}{l}\text { Findings with } \\
\text { infarct }\end{array}$ & $\begin{array}{l}p \text { value } \\
\text { death }\end{array}$ & $\begin{array}{l}p \text { value } \\
\text { infarct }\end{array}$ \\
\hline \multicolumn{8}{|c|}{ Q and QS patterns } \\
\hline $1: 1$ & Q and QS pattern & 944 & 15 & $2(13)$ & $3(20)$ & & \\
\hline $1: 2$ & Q, QS, and QSR pattern & 942 & 16 & $1(6)$ & $3(19)$ & & \\
\hline \multicolumn{8}{|c|}{ STJ and segment depression } \\
\hline $4: 1$ or $4: 2$ & STJ depression & 926 & 18 & $4(22)$ & $4(22)$ & 0.054 & 0.041 \\
\hline T wave items & T wave negative or biphasic & & & & & & \\
\hline $5: 1$ or $5: 2$ & & 924 & 19 & $4(21)$ & $5(26)$ & 0.072 & 0.006 \\
\hline \multicolumn{8}{|c|}{ AV conduction defect } \\
\hline $6: 1$ & Complete AV block & 945 & 0 & & & & \\
\hline $6: 4: 1$ & Wolf-Parkinson-White pattern & 945 & 0 & & & & \\
\hline $6: 8$ & Artificial pacemaker & 945 & 0 & & & & \\
\hline \multicolumn{8}{|c|}{ Ventricular conduction defect } \\
\hline $7: 1: 1$ & $\begin{array}{l}\text { Complete left bundle branch } \\
\text { block }\end{array}$ & 945 & 1 & 0 & 0 & & \\
\hline $7: 2: 1$ & $\begin{array}{l}\text { Complete right bundle } \\
\text { branch block }\end{array}$ & 945 & 9 & $1(11)$ & $2(22)$ & & \\
\hline $7: 3$ & Incomplete RBB & 945 & 26 & $3(12)$ & $5(19)$ & & \\
\hline $7: 4$ & Intraventricular block & 944 & 4 & 0 & 0 & & \\
\hline $7: 6$ & Incomplete LBB & 919 & 5 & $1(20)$ & $1(20)$ & & \\
\hline
\end{tabular}

The $p$ values refer to death and infarct risk comparisons between persons with and without ECG abnormalities. Only $p$ values smaller than 0.100 are shown. Note that the $p$ values themselves are due to variation. Even one single finding more or less might change the $p$ value substantially. Percentages in brackets

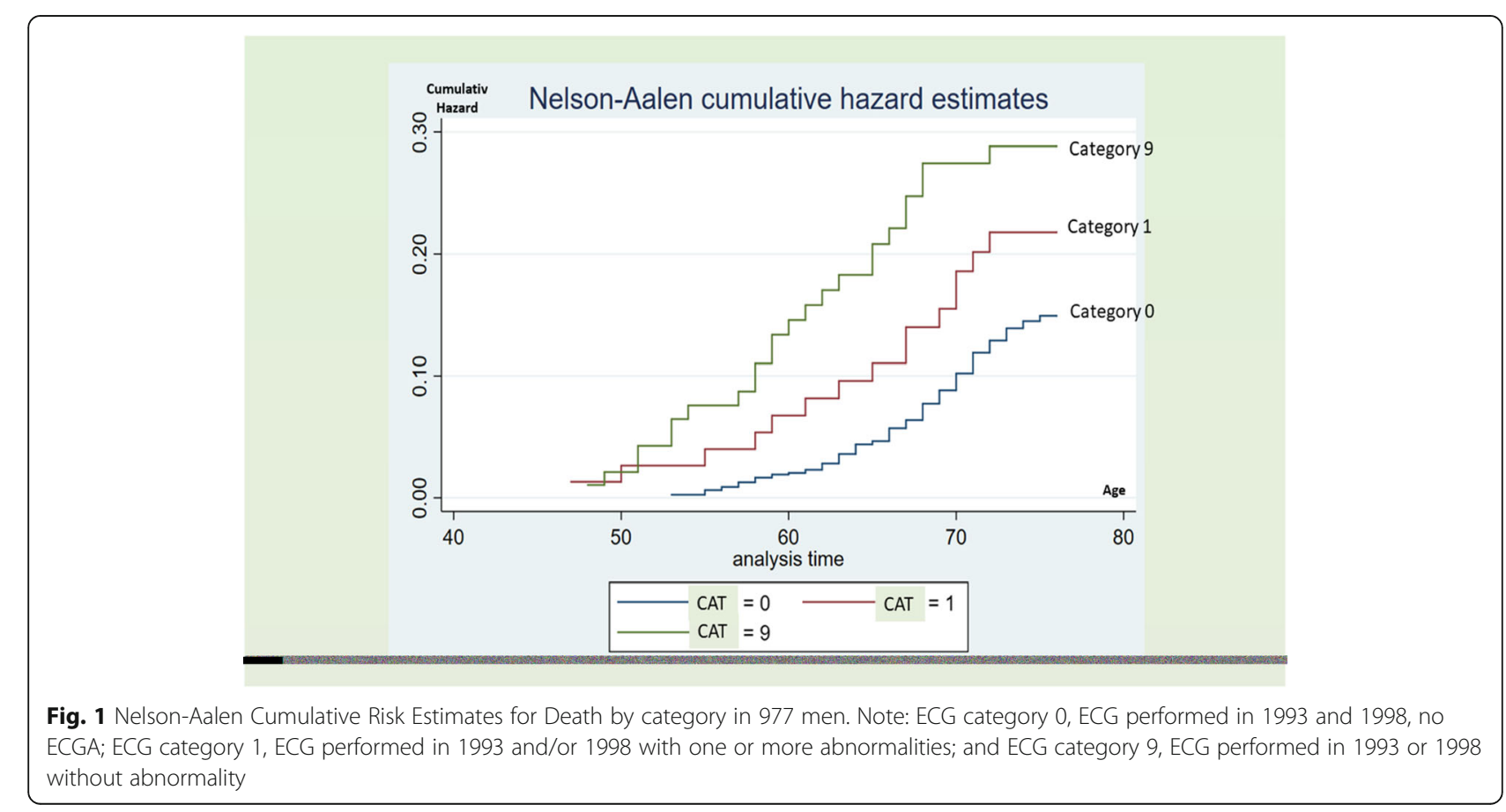




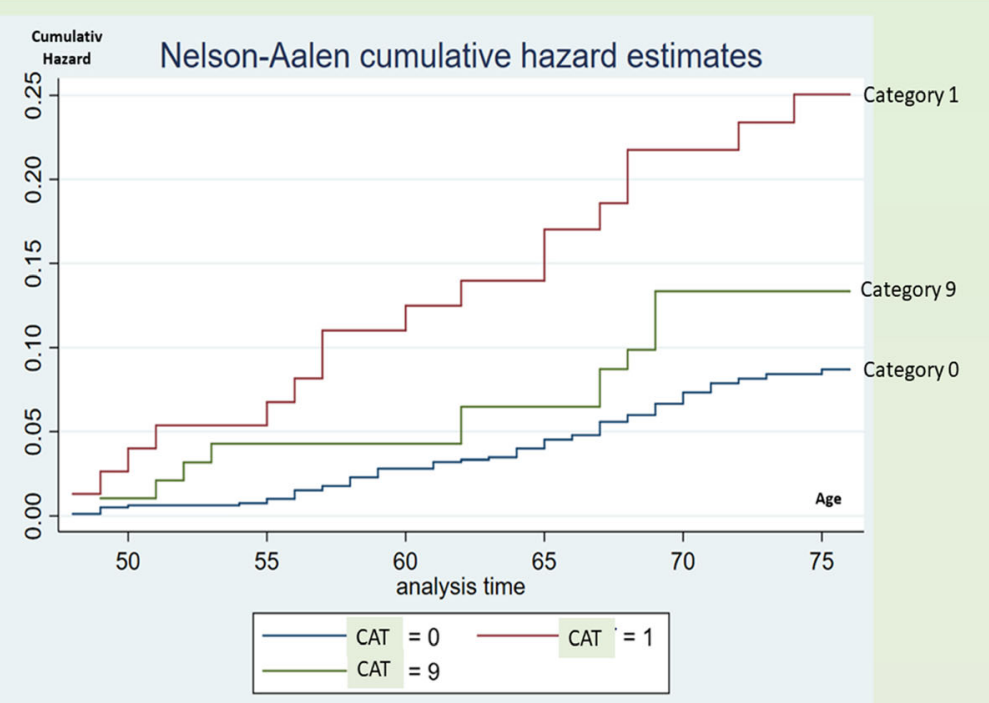

Fig. 2 Nelson-Aalen Cumulative Risk Estimates for Myocardial Infarction by category in 977 men. Note: ECG category 0, ECG performed in 1993 and 1998, no ECGA; ECG category 1, ECG performed in 1993 and/or 1998 with one or more abnormalities; and ECG category 9, ECG performed in 1993 or 1998 without abnormality

cholesterol and hypertension, making the baseline risk factors obsolete in some cases.

Although we do not have secular, longitudinal data of the 25-year period, the findings presented in another longitudinal Swedish study of 50-year-old men followed for 50 years which show secular changes: smoking less, lower cholesterol but higher BMI, and a more sedentary lifestyle in cardiovascular risk factors over time are likely to apply to our cohort [38]. Furthermore, the addition of medication during this period may have changed the prognosis of some endpoints.

\section{Conclusions}

The study showed that there was an about 3- to 4-fold independent risk for a first $\mathrm{MI}$ in persons with at least one ECGA compared to those with normal ECGs found in resting ECGs of healthy Swedish working men aged 45 to 50 years over the following 25 years. A 12-lead resting ECG should be included in any MI risk calculation on an individual level.

A parallel statement for death could not be made.

Presence of ST- and R-wave changes are predictors of MI risk but not of death and adds some information of MI risk variation to that which can be obtained using the Framingham Risk Index.

The highest Pseudo-R2 observed in the study is found to be a predictor of a MI model with 20 independent variables. It reaches almost $25 \%$, however, meaning that we must assume that there is still a large number of variables, not observable or totally unknown that influence the risks.

\section{Supplementary Information}

The online version contains supplementary material available at https://doi. org/10.1186/s43044-020-00114-9.

Additional file 1: Appendix 1. The Renault-Volvo Coeur project group 1993-1998.

\section{Abbreviations}

Cl: Confidence interval; CVD: Cardiovascular disease;

ECG: Electrocardiography; ECGA: Electrocardiography abnormality; FRI: Framingham Risk Index; FRS: Framingham Risk Score; HR: Hazard ratio; ICD: International Classification of Diseases; MC: The Minnesota Code Classification System for Electrocardiographic Findings; MI: Myocardial infarction; OR: Odds ratio; Pseudo-R2: Calculation of how much of the outcome variation is explained by the model; P-Value: Probability value; QRScomplex: An ECG pattern that symbolizes the depolarization of ventricles; QTc: An ECG pattern that measures the time between ventricles depolarization and ventricles repolarization corrected for pulse rate; RR: Relative risk; STJ: ST-junction = an ECG pattern symbolizes phase 2 of ventricular repolarization; T-Wave: An ECG pattern symbolizes phase 3 of ventricular repolarization; USPSTF: US Preventive Services Task Force; WHO: World Health Organization

\section{Acknowledgements}

Appendix 1 lists all persons that have contributed to the Renault-Volvo Coeur study to whom we are deeply indebted.

\section{Authors' contributions}

LD designed the study and rewrote the manuscript provided by PE. BE made all statistical calculations, wrote the "Statistical analysis" section and the "Confounding" and "Bias" sections and added thoughtful comments to the "Discussion" section. All authors have read and approved the manuscript; however, $\mathrm{BE}$ is deceased and has not read the final version.

\section{Funding}

All investigations of the Swedish men through 1998 were paid for by the Volvo Research Foundation (H92:37). No added funding was available for the present study. 


\section{Availability of data and materials}

May be available upon request to the corresponding author.

\section{Ethics approval and consent to participate}

The Research Ethics Committee of Gothenburg University approved the original study protocol and the consent to participate form on 11 February 1993 (Dnr 23-93). The Research Ethics Committee of Gothenburg University renewed their approval of a changes study protocol on 19 February 2019 (Dnr1212-18/2019-00316). For the present study, the need to consent was waivered by the ethics committee since only registered information was collected and anonymized.

\section{Consent for publication}

Not applicable.

\section{Competing interests}

None.

\section{Author details}

Department of Public Health and Community Medicine, the Sahlgrenska Academy, University of Gothenburg, Box 454, SE-405 30 Gothenburg, Sweden. ${ }^{2}$ Department of Health Metrics, the Sahlgrenska Academy, University of Gothenburg, Gothenburg, Sweden.

Received: 15 August 2020 Accepted: 21 October 2020 Published online: 30 October 2020

\section{References}

1. World Health Organization (2020). Cardiovascular diseases. http://www.euro. who.int/en/health-topics/noncommunicable-diseases/cardiovasculardiseases/cardiovascular-diseases2. Accessed 13 Apr 2020

2. Mahmood L, Vasan W (2013) The Framingham Heart Study and the epidemiology of cardiovascular disease: a historical perspective. Lancet. 383:999-1008

3. Galen of Pergamon : Ars Medica (ca 150 AD) in Hygiene, volume 1, Loeb classical library. ISBN 9780674997127

4. Tunstall-Pedoe H, Kuulasmaa K, Amoyel P, Rajakangos AM, Pajak A (1991) WHO MONICA Project. Myocardial infarction and coronary deaths in the WHO-Monica project. Registration procedures, event rates and case-fatality rates in 38 populations from 21 countries in 4 continents. Circulation 90: 583-612. https://doi.org/10.1161/01.cir.90.1.583

5. loannou A, Papageorgiou N, Singer D, Missouris CG (2018) Registry report of the prevalence of ECG abnormalities and their relation to patient characteristics in an asymptomatic population. QJM. 111(12):875-879

6. Jonas D, Reddy S, Cook Middleton J, Barclay C, Green J, Baker C, Asher G (2018) Screening for cardiovascular disease risk with resting or exercise electrocardiography. evidence report and systematic review for the US Preventive Services Task Force. JAMA 319:2315-2328. https://doi.org/10.1001/jama.2018.6897

7. Simon A, Dimberg L, Levenson J, Lanoiselée C, Massonneau M, Eriksson B, Jern S, Kumlin L, Marin P, Dahlof B, Hansson L, Bjorntorp P (1997) Comparison of cardiovascular risk profile between male employees of two automotives companies in France and Sweden. The Coeur Project Group. Eur J Epidemiol. 13(8):885-891

8. Tunstall-Pedoe H, Kuulasmaa K, Amoyel P, Rajakangos AM, Pajak A (1991) WHOMONICA Project. Myocardial infarction and coronary deaths in the WHOMonica project. Registration procedures, event rates and case-fatality rates in 38 populations from 21 countries in 4 continents. Circulation 90:583-612

9. Tunstall-Pedoe H (1988) Autres pays, autres mors. BMJ 297:1559-1560

10. D'Agostino RB Sr, Vasan RS, Pencina MJ, Wolf PA, Cobain M, Massaro JM, Kannel WB (2008) General cardiovascular risk profile for use in primary care: the Framingham Heart Study. Circulation 117:743-753. https://doi.org/10. 1161/CIRCULATIONAHA.107.699579

11. Kumlin L, Latscha G, Orth-Gomer K, Dimberg L, Lanoiselée C, Simon A, Eriksson B, Coeur Study Group (2001) Marital status and cardiovascular risk in French and Swedish automotive industry workers--cross sectional results from the Renault-Volvo Coeur study. J Intern Med. 249(4):315-323

12. Rose G, Kumlin L, Dimberg L, Bengtsson C, Orth-Gomér K, Cai X (2006) Work-related life events, psychological well-being and cardiovascular risk factors in male Swedish automotive workers. Occup Med (Lond) 56:386392. https://doi.org/10.1093/occmed/kql037

13. Denarie N, Simon A, Chironi G, Gariepy J, Kumlin L, Massonneau M, Lanoiselee C, Dimberg L, Levenson J (2001) Difference in carotid artery wall structure between Swedish and French men at low and high coronary risk. Stroke. 32(8):1775-1779

14. Kumlin L, Dimberg L, Marin P (1997) Ratio of abdominal sagittal diameter to height is strong indicator of coronary risk. BMJ. 314(7083):830

15. Dimberg L, Eriksson B, Hashem M (2019) Myocardial infarction and death findings from a 22-year follow-up of a cohort of 980 employed Swedish men. Public Health 175:148-155. https:/doi.org/10.1016/j.puhe.2019.07.006 Epub 2019 Sep 5

16. Km A, Odell PM, Wilson PW et al (1991) Cardiovascular disease risk profiles. Am Heart J. 121(1 Pt 2):293-298

17. Prineas RJ, Crow RS, Blackburn H (1982) The Minnesota Code Manual of Electrocardiographic Findings. John Wright PSB, Boston, p 203

18. Swedeheart, 2020. https://www.ucr.uu.se/swedeheart/ Accessed 13 Apr 2020.

19. Thygesen K, Alpert JS, White HD (2007) Joint esc/accf/aha/whf task force for the redefinition of myocardial infarction. Universal definition of myocardial infarction. Eur Heart J. 28(20):2525-2538. https://doi.org/10.1093/eurhearti/ehm355

20. WHO International classification of diseases https://www.who.int/ classifications/icd/en/ Accessed 14 Apr 2020

21. McFadden D (1978) Qualitative methods for analyzing travel behavior of individuals: some recent developments. In: Henscher DA, Stopher PR (eds) Behaviour modelling, pp 279-318

22. US Preventive Services Task Force, Sj C, Krist AH et al (2018) Screening for cardiovascular disease risk with electrocardiography. JAMA 319(22):230814

23. Groot A, Bots ML, Rutten FH et al (2015) Measurement of ECG abnormalities and cardiovascular risk classification: a cohort study of primary care patients in the Netherlands. Br J Gen Pract. 65(630):e1-e8

24. Laukkanen JA, DI Angelantionio E, Khan H et al (2014) T-wave inversion, QRS duration, and QRS/T angle as electrocardiographic predictors of the risk for sudden cardiac death. AM J Cardiol 113:1178-1183

25. Aro AL, Anttonen O, Tikkanen JT et al (2011) Intraventricular conduction delay in a standard 12-lead electrocardiogram as a predictor of mortality in the general population. Circ Arrhythm Electrophysiol 4(5):704-710

26. Badheka AO, Singh V, Pael NJ et al (2013) QRS duration on electrocardiography and cardiovascular mortality (from the National Health and Nutrition Examination Survey-III). Am J Cardiol 112(5):671-677

27. Dean JF, Rhoades DA, Noonan C et al (2017) Comparison of QRS duration and associated cardiovascular events in American Indian men versus women (The Strong Heart Study). Am J Cardiol 119(11):1757-1762

28. Kurl S, Mäkikallio TH, Laukkanen JA (2015) T-wave inversion and mortality risk. Ann Med. 47(1):69-73

29. Rollin A, Maury P, Kee F et al (2016) Isolated negative T waves in the general population is a powerful predicting factor of cardiac mortality and coronary heart disease. Int J Cardiol. 203:318-324

30. Vilanova MB, Mauri-Capdevila G, Sanahuja J et al (2015) Prediction of myocardial infarction in patients with transient ischaemic attack. Acta Neurol Scand 131:111-119

31. Boulanger $M$, Bejot $Y$, Rothwell PM et al (2018) Long-term risk of myocardial infarction compared to recurrent stroke after transient ischemic attack and ischemic stroke: systematic review and meta-analysis. J Am Heart Assoc 7(2):e007267 34

32. Dekker JM, Schouten EG, Klootwijk P et al (1994) Association between QT interval and coronary heart disease in middle-aged and elderly men. The Zutphen Study. Circulation 90:779-785

33. Nielsen JB, Graff C, Rasmussen PV et al (2014) Risk prediction of cardiovascular death based on the QTC interval: evaluating age and gender differences in a large primary care population. Eur Heart J. 35:1335-1344

34. Sauer AJ, Moss AJ, McNitt S et al (2007) Long QT syndrome in adults. J Am Coll Cardiol. 49:329-337

35. Yap J, Jin AZ, Nyunt SZ et al (2016) Longitudinal community-based study of QT interval and mortality in Southeast Asians. PLoS One. 11(5):e0154901

36. National Institute for Health and Care Excellence (NICE) (2014) Cardiovascular disease: risk assessment and reduction, including lipid modification. Clinical guideline [CG181]. NICE, London

37. De Ruijter W, Westendorp RG, Assendelft WJ et al (2009) Use of Framingham risk score and new biomarkers to predict cardiovascular mortality in older people: population based observational cohort study. BMJ. 338:a3083

38. Zhong Y, Rosengren A, Fu M et al (2017) Secular changes in cardiovascular risk factors in [39]: The study of men born in 1913, 1923, 1933, 1943, 1953 and 1963. Eur J Prev Cardiol. 24(6):612-620

\section{Publisher's Note}

Springer Nature remains neutral with regard to jurisdictional claims in published maps and institutional affiliations. 